\title{
Survival of Foodborne Pathogens in Homemade Fig and Mulberry Vinegars
}

\author{
İlkin Yücel Şengün ${ }^{1, a, *}$, Gülden Kılıç̧,b \\ ${ }^{1}$ Department of Food Engineering, Engineering Faculty, Ege University, 35100 Bornova/Izmir, Turkey \\ *Corresponding author \\ A R T I C L E I N F O A B S T R A C T \\ Research Article \\ This work reports the survival status of Listeria monocytogenes, Escherichia coli O157:H7, \\ Staphylococcus aureus and Salmonella Typhimurium in homemade fig and mulberry vinegar. Each \\ pathogen was separately inoculated in vinegar samples at approximately $7 \log \mathrm{CFU} / \mathrm{mL}$. The \\ survival status of pathogens was examined at $20^{\circ} \mathrm{C}$ for $0,15,30$ and $60 \mathrm{~min}$, and 4,8 and $24 \mathrm{~h}$. The \\ Received : 02/01/2020 \\ Accepted : 31/08/2020 \\ residual populations after $24 \mathrm{~h}$ were below detection limit for all species assayed. $S$. Typhimurium \\ was much more sensitive to mulberry vinegar ( $\cong 6 \log$ reduction in $30 \mathrm{~min})$ than it is to fig vinegar

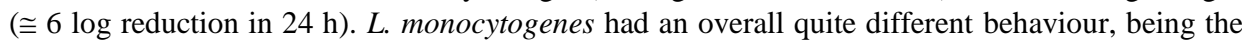 \\ most sensitive species to fig vinegar ( $\cong 6 \log$ reduction in $4 \mathrm{~h}$ ) while being the most resistant one to \\ mulberry vinegar $(\cong 6 \mathrm{log}$ reduction in $24 \mathrm{~h})$. The total phenolic content of fig vinegar $(767 \mathrm{mg}$ \\ GAE/L) was higher than mulberry vinegar (557.5 $\mathrm{mg}$ GAE/L). The results exhibited that \\ Keywords: \\ antimicrobial activity of vinegar is mainly related to the contact time, test pathogen and \\ Homemade vinegar \\ Fig \\ physicochemical properties of vinegar.
}

Mulberry

Survival

Foodborne pathogens

ilkin.sengun@ege.edu.tr

iD https://orcid.org/0000-0002-9445-5166

|b@gulden-gk@hotmail.com

https://orcid.org/0000-0001-6125-6219

(c) (1) (8) This work is licensed under Creative Commons Attribution 4.0 International License

\section{Introduction}

Vinegar is a product performed by the activity of yeasts (Saccharomyces cerevisiae) and acetic acid bacteria $(\mathrm{AAB})$, which is used as flavouring and preserving agent to foodstuffs (Sengun, 2015). It has also long been used in natural and traditional folk medicine for the aim of treating various diseases (Karabiyikli and Sengun, 2017). Various types of vinegars produced worldwide with different names and sensory properties by different production system and raw material used (Solieri and Giudici, 2009).

Recently, the popularity of unpasteurized traditional kinds of vinegar prepared at homes from a variety of substrates having fermentable sugar, has been increased because of their health benefits. Although the substrates and the final products of homemade vinegar have some differences, the process always includes alcoholic and acetous fermentation, which are the main steps of vinegar production (Rosma et al., 2016). Unlike commercial vinegar, they are produced under uncontrolled conditions and consumed without pasteurization. Hence, it may provide an appropriate medium for the growth of undesirable microorganisms. It is noted that the presence of sufficient amount of acid is essential to obtain high quality vinegar (Giudici et al., 2017).

Fig (Ficus carica) is native in Anatolia and important agricultural crop for Turkey (Simsek, 2010). Phytochemical studies revealed that this fruit contains numerous bioactive components and shows antioxidant, antiviral, antibacterial, anti-inflammatory, haemostatic, hypoglycaemic, hypocholesterolaemia, anticancer and anthelmintic effects (Young-Soo and Cha, 2010). Fig has traditionally been used to produce vinegar mainly for home consumption in Turkey. The various steps in the production of fig vinegar include mixing fruits and water, first fermentation (2 weeks), filtration, second fermentation (10-12 weeks) and bottling (Sengun, 2013). Except our previous studies (Sengun et al., 2020; Şengün and Kilıç, 2020), there are no studies investigating the physicochemical and antimicrobial properties of fig vinegar.

Mulberry (Morus alba) grows in a wide area of subtropical, tropical and temperate zones in Africa, Asia, Europe, South America, and North America. Recently, the popularity of mulberry has been enhanced because of its 
nutritional and therapeutic characteristics (Zou et al., 2015). Traditionally, the fruits, which have a short shelflife, have been processing into various products like mulberry jam, juice, syrup, vinegar and some traditional products such as 'mulberry kome' and/or 'mulberry pestil' in Turkey (Okatan et al., 2016). The production of mulberry vinegar is similar to fig vinegar, as described above. It was reported that mulberry vinegar contains higher amount of lactic and succinic acids than other fruit vinegar (Chang et al., 2005). There are also few reports on the antioxidant and antimicrobial properties of mulberry vinegar (Chang et al., 2005; Karaagac et al., 2016).

Although the antibacterial microbial action of vinegar has been investigated previously by various researchers, these studies mostly dealing with the industrial grape and apple vinegar. Moreover, there is limited knowledge on traditional homemade vinegar produced from different raw materials. Therefore, the purpose of the present study was to 1) determine the physicochemical properties of traditionally produced homemade fig and mulberry vinegar, 2) investigate the survival of diverse food-borne pathogens (Listeria monocytogenes, Escherichia coli O157:H7, Staphylococcus aureus and Salmonella Typhimurium) in fig and mulberry vinegar.

\section{Materials and Methods}

\section{Vinegar Samples}

In this study, two vinegar samples were used for test material. Traditionally produced homemade fig and mulberry vinegar were collected from Aydin and Kars cities of Turkey, respectively. The vinegar production is performed by two-stage: In the first step, fresh fruit and water $(1: 1, \mathrm{w} / \mathrm{v})$ is mixed in a wide mouth bottle covered with cheesecloth and fermented for 2 to 3 weeks. Secondly, the mixture is filtrated and the fermented juice, separated from the fruits, left for second fermentation at room temperature for 10 to 12 weeks. After desired acidity is obtained, vinegar samples were kept at $4^{\circ} \mathrm{C}$ in closed bottles. The collected samples were also kept at $4^{\circ} \mathrm{C}$ before used in the analysis.

\section{Physicochemical Properties of Vinegar Samples}

The $\mathrm{pH}$ value of vinegar samples was determined by using a pH meter (NEL Mod 821). The total acidity of the vinegar samples was measured by titration and indicated as $\mathrm{g}$ acetic acid/100 mL sample (AOAC, 1995).

Brix values of vinegar samples were detected by a refractometer (Hanna HI 96801) (Anon, 1991).

The Folin-Ciocalteu colorimetric method was used to investigate the total phenolic contents of vinegar samples (Cemeroglu, 2013). It is determined using a calibration curve created with different concentration of gallic acid and the absorbance of vinegar samples was measured by a spectrophotometer (Agilent Technologies, Carry60 UVVisible) at $720 \mathrm{~nm}$. The results were indicated as $\mathrm{mg}$ gallic acid equivalents (GAE)/L. Analysis were performed in three replicates.

\section{Microbiological Properties of Vinegar Samples}

To detect the microbiological properties of fig and mulberry vinegar, $25 \mathrm{~mL}$ of vinegar sample was taken and then transferred in $225 \mathrm{~mL}$ of peptone water $(\mathrm{PW}, 0.1 \%$, pH
$6.3 \pm 0.2$, Oxoid, Basignstoke, England) under aseptic conditions. Ten-fold dilutions of the sample were prepared in PW, and then appropriate dilutions were plated on suitable media in parallel to evaluate microbial counts.

For the enumerations of acetic acid bacteria (AAB), lactic acid bacteria (LAB) and mould-yeast, Glucose Yeast Extract Calcium Carbonate Agar (GYC, 1\% yeast extract, $1.5 \%$ agar, $2 \%$ calcium carbonate, $10 \%$ glucose, $\mathrm{pH}$ 6.8 \pm 0.2 ) (De Vero et al., 2006), Man Rogosa and Sharp Agar (MRS, pH 6.2 \pm 0.2 , Oxoid) (ISO 15214, 1998) and Potato Dextrose Agar (PDA, pH 5.6 \pm 0.2 , Oxoid) acidified (10\% tartaric acid (Merck, Germany)) (FDA-BAM, 2001a) were used, respectively. The samples were also checked for the occurrence of L. monocytogenes (FDA-BAM, 2017), E. coli O157:H7 (FDA-BAM, 2002), S. aureus (FDABAM, 2001b) and Salmonella spp. (FDA-BAM, 2016).

\section{Survival Status of Pathogens in Vinegar Samples}

In the study, the main pathogens associated with foodborne diseases including Listeria monocytogenes Scott A, Escherichia coli O157:H7 ATCC 43895, Staphylococcus aureus 6538P and Salmonella Typhimurium NRRL-B-4420 were used as test cultures.

Test cultures were supplied from Food Microbiology Research Laboratory of Food Engineering Department, at Ege University, Izmir, Turkey. The test cultures stored at $20^{\circ} \mathrm{C}$ were reactivated for several times in Tryptic Soy Broth (TSB, pH 7.3 \pm 0.2 , Oxoid) (incubated at $37^{\circ} \mathrm{C}$ for 18 $24 \mathrm{~h}$ ). The initial counts were investigated by plating the regularly diluted suspension of each culture on Tryptic Soy Agar (TSA, pH 7.3 \pm 0.2 , Oxoid).

To determine the survival status of bacterial cultures in vinegar samples, $9 \mathrm{~mL}$ sterilized vinegar was inoculated with $1 \mathrm{~mL}$ of culture (approximately $7.0 \log \mathrm{CFU} / \mathrm{mL}$ ), separately. Then pathogen inoculated tubes were placed at $20^{\circ} \mathrm{C}$ and analysed at $0,15,30$ and $60 \mathrm{~min}$, and 4, 8 and 24 h. Uninoculated vinegar samples were also used as negative control. For counting the numbers of microorganisms, samples from each tube were taken at predetermined periods, diluted in PW and spread on TSA. After incubation at $37^{\circ} \mathrm{C}$ for $24 \mathrm{~h}$, colonies were enumerated.

\section{Statistical Analysis}

All analysis were conducted in two parallels and three replicates. Data were examined by one-way ANOVA and Duncan's Multiple Range test at the significance level of $\mathrm{P}<0.05$ by the SPSS software version 15 for Windows Software Package. The values were showed in terms of standard deviation and mean values in figures and tables (SPSS, 2004).

\section{Results and Discussion}

\section{Physicochemical Properties of Vinegar Samples}

The $\mathrm{pH}$ values were found as $3.75 \pm 0.21$ in fig vinegar and $2.87 \pm 0.43$ in mulberry vinegar. The total acidity of vinegar samples was determined as $3.67 \pm 0.35$ and $4.07 \pm 0.16 \mathrm{~g}$ acetic acid $/ 100 \mathrm{~mL}$ for fig and mulberry vinegar, respectively (Table 1). Vinegar that are sold at the retail level should contain a minimum acidity of $4 \%(\mathrm{w} / \mathrm{v})$ in Turkey and United States (FDA, 1995; Anon, 2016). The acidity of vinegar should be at least $5 \%(\mathrm{w} / \mathrm{v})$ according to 
regional standards of European Countries (EC, 1999). In the current study, acidity of fig vinegar, which was found lower than mulberry vinegar, was not in conformity with European Union, Turkish and United States regulations. This result shows the possibility of the growth of undesirable microorganisms in fig vinegar. Since, proper acid content is important to eliminate the contaminants for quality, safety and stability of the vinegar (Giudici et al., 2017). In the previous study, the $\mathrm{pH}$ and total acidic values of the fig vinegar were ranged between 3.05-3.73 and 2.10$6.97 \mathrm{~g}$ acetic acid/100 mL, respectively (Sengun, 2013). The total acidity reported by Budak (2015) for mulberry vinegar (5.72 $\mathrm{g}$ acetic acid/100 $\mathrm{mL})$ was slightly higher than the present result. In the previous study, the $\mathrm{pH}$ value and total acidity of apple, apricot, blackberry, fig, grape, mandarin, persimmon, pomegranate, plum, and rosehip vinegar were ranged between 3.22-3.85 and 1.11-5.61\% acetic acid, respectively, while fig vinegar had lower $\mathrm{pH}$ value (3.22) and higher total acidity $(4.73 \%$ acetic acid) than the vinegar investigated in the present study (Sengun et al., 2020). It was reported that the nature and amount of the organic acids available in vinegar offer information for its origin and, about the processing techniques (Solieri and Giudici, 2009).

Brix is used as an index for an amount of sugar and to differentiate certain types of vinegar, like traditional balsamic vinegar which could be recognized with high amount of brix (Giudici et al., 2015). In this study, brix value of fig and mulberry vinegar was 21.2 and 5.6, respectively (Table 1). In previous studies, brix value of mulberry vinegar was found as 3.10 (Budak, 2015). There is no study available in the literature concerning the brix of traditional fig vinegar. Ozturk et al. (2015) determined brix values of traditional homemade vinegar samples ranging between 1.02 and 20.80. Hence, high changeability could be observed in brix values of different vinegar samples.

The total phenolic content of fig and mulberry vinegar was $767 \pm 8.48 \mathrm{mg} \mathrm{GAE} / \mathrm{L}$ and $557.5 \pm 28.99 \mathrm{mg} \mathrm{GAE} / \mathrm{L}$, respectively (Table 1). Although total phenolic content in mulberry vinegar have been reported before $(972.708 \mathrm{mg}$ GAE/L) by Budak (2015), to our knowledge, the total phenolic content of fig vinegar is estimated for the first time in this study. The total phenolic contents of the traditional vinegar samples were ranged between $75.01-2228.79 \mathrm{mg}$ GAE/L for grape vinegar and 40.44-434.88 mg GAE/L for apple vinegar (Ozturk et al., 2015), these values were determined as 933-1162 mg GAE/L for various fruit vinegar samples (Sengun et al., 2020). It was stated that the total phenolic content of vinegar varies in a large variety, based on the production method and raw material used in vinegar (Sengun, 2015).

\section{Microbiological Properties of Vinegar Samples}

The number of AAB, which are known as the main group responsible for the production of acetic acid, was 2.54 and $2.84 \log \mathrm{CFU} / \mathrm{mL}$ for fig and mulberry vinegar, respectively (P>0.05) (Table 2). Acid-tolerant microorganisms, mainly $\mathrm{AAB}$, can grow and keep alive active as metabolic at high amount of acetic acid (Gullo et al., 2009). In addition, lots of undesirable microorganisms from environment and raw materials could not viable in the harsh fermentation medium of vinegar. Although fig and mulberry vinegar were found negative for the presence of pathogens tested, they were insufficient to complete elimination of LAB and mold-yeast flora of the samples (Table 2). In the previous study, AAB, total mesophilic aerobic bacteria, LAB and mold-yeast of traditional fig vinegar collected from different regions were in the range of 2.68-8.23, 2.26-7.29, 0.81-8.20 and <1.00-6.49 $\log \mathrm{CFU} / \mathrm{mL}$, respectively (Sengun, 2013). In the study performed by Ozturk et al. (2015), the counts of LAB, AAB and mold-yeast of 20 traditional homemade vinegar samples were ranged between $<10-1.1 \times 10^{9},<10-7.2 \times 10^{6}$ and $<10-3.9 \times 10^{6}$ $\mathrm{CFU} / \mathrm{mL}$, respectively. It was reported that the factors that determine the dominance of some microorganisms in vinegar are dependent on some parameters such as media composition, humidity and temperature (Giudici et al., 2017). The acid and ethanol, obtained in the first stages of spontaneous fermentation by LAB and yeast, respectively, prevent the growth of unwanted microorganisms, influencing extension of the shelf life of vinegar (Rosma et al., 2016). On the other hand, vinegar produced by spontaneous fermentation has a great risk of spoilage (Solieri and Giudici, 2009).

Table 1. Physicochemical properties of vinegar samples

\begin{tabular}{l|cc}
\hline \multicolumn{1}{c|}{ Analysis } & Fig vinegar & Mulberry vinegar \\
\hline $\mathrm{pH}$ & $3.75 \pm 0.21^{\mathrm{a}}$ & $2.87 \pm 0.43^{\mathrm{a}}$ \\
Total acidity & $3.67 \pm 0.35^{\mathrm{a}}$ & $4.07 \pm 0.16^{\mathrm{a}}$ \\
(g acetic acid/100mL) & $21.2 \pm 0.00^{\mathrm{b}}$ & $5.60 \pm 0.00^{\mathrm{a}}$ \\
Brix & $767 \pm 8.48^{\mathrm{b}}$ & $557.5 \pm 28.99^{\mathrm{a}}$ \\
Total phenolic content & \\
\hline (mg GAE/L) & & \\
\hline
\end{tabular}

Standard deviation of means is shown as \pm SD. Values in the same row with different superscripts $(\mathrm{a}, \mathrm{b})$ are statistically different $(\mathrm{P}<0.05)$.

Table 2. Microbiological properties of vinegar samples

\begin{tabular}{l|cc}
\hline \multicolumn{1}{c|}{ Microbial Counts } & $\begin{array}{c}\text { Fig vinegar } \\
(\text { Log CFU/mL) }\end{array}$ & $\begin{array}{c}\text { Mulberry vinegar } \\
\text { (Log CFU/mL) }\end{array}$ \\
\hline Acetic Acid Bacteria & $2.54 \pm 0.05$ & $2.84 \pm 0.08$ \\
Lactic Acid Bacteria & $1.91 \pm 0.05^{\mathrm{a}}$ & $3.17 \pm 0.04^{\mathrm{b}}$ \\
Mold and Yeast & $1.44 \pm 0.08$ & $1.32 \pm 0.07$ \\
E. coli O157:H7 & $\mathrm{ND}$ & $\mathrm{ND}$ \\
L. monocytogenes & $\mathrm{ND}$ & $\mathrm{ND}$ \\
S. Typhimurium & $\mathrm{ND}$ & $\mathrm{ND}$ \\
S. aureus & $\mathrm{ND}$ & $\mathrm{ND}$ \\
\hline
\end{tabular}

*ND: Not detected. Standard deviation of means is shown as \pm SD. Values in the same row with different superscripts $(a, b)$ are statistically different $(\mathrm{P}<0.05)$.

\section{Survival of The Pathogens in Vinegar Samples}

The initial populations of pathogens $(0 \mathrm{~min})$ were ranged from 5.63 to $6.65 \log \mathrm{CFU} / \mathrm{mL}$ in fig vinegar and 5.61 to $6.31 \log \mathrm{CFU} / \mathrm{mL}$ in mulberry vinegar. The inhibition effect of vinegar samples, which increased by increasing treatment time, showed differences depending on test pathogens used (Figures 1-4).

L. monocytogenes decreased below detection limit after $4 \mathrm{~h}$ exposure to fig vinegar. Reducing numbers of $L$. monocytogenes were related with the rising treatment time and significance was observed between treatment times of 0,15 and $30 \mathrm{~min} \quad(\mathrm{P}<0.05)$ (Figure 1). Moreover, significant differences were not found between treatment times (except $24 \mathrm{~h}$ ) during the survival status of $L$. monocytogenes in mulberry vinegar $(\mathrm{P}>0.05)$. According to the results, L. monocytogenes was more resisting in 
mulberry vinegar than in fig vinegar (Figure 1). It seems reasonable to conclude that in fig vinegar, a high amount of phenolic contents provides an additive or synergistic antilisterial effect to that of organic acids. The powerful bactericidal effect of fig vinegar could possibly be linked with the existing compounds having antimicrobial properties due to fig fermentation and fig itself. It is stated that fig includes one of the highest amounts of polyphenols among the frequently consumed foods such as fruits and beverages (Bachir bey et al., 2014). Strong inhibitory effects of phenolic compounds were also evaluated by Ramos et al. (2014). In the study, it was compared the antilisterial characteristics of balsamic vinegar with acetic acid solution and white wine vinegar. Maximum reduction of L. monocytogenes (2.15 log CFU/g) was provided by immersion lettuce in balsamic vinegar (Ramos et al., 2014) while more than about $1 \log$ unit reduction was achieved by acetic acid treatment up to approximately $1.0 \%$ concentration as observed in the other studies (Nastou et al., 2012; Ramos et al., 2014). It was also reported that variety of vinegar are rich in phenolic compounds, which indicate antimicrobial and antioxidant activities (Karabiyikli and Sengun, 2017).

The number of E. coli $\mathrm{O} 157: \mathrm{H} 7$ inoculated in fig vinegar was significantly decreased to $3.83 \log \mathrm{CFU} / \mathrm{mL}$ for $4 \mathrm{~h} \quad(\mathrm{P}<0.05)$, while there was not a significant difference between the treatment times of $0,15,30$ and 60 min $(\mathrm{P}>0.05)$ (Figure 2). Moreover, fig vinegar decreased the counts of $E$. coli $\mathrm{O} 157: \mathrm{H} 7$ to an undetectable level after $24 \mathrm{~h}$. The survival status of E. coli $\mathrm{O} 157: \mathrm{H} 7$ in mulberry vinegar showed similar pattern with fig vinegar (Figure 2). E. coli $\mathrm{O} 157: \mathrm{H} 7$ is considered to be an intrinsically acidresistant bacterium, surviving actually unaffected during 2 to $7 \mathrm{~h}$ exposures at $37^{\circ} \mathrm{C}$ and $\mathrm{pH} 2.5$ (Benjamin and Datta, 1995; Buchanan et al., 2004). The pathogen has been shown experimentally to survive in a various of foods including acid, such as black mulberry juice, apple cider, red muscadine juice, blackberry juice (Zhao et al., 1993; Kim et al., 2009; Karabiyikli et al., 2012; Yang et al., 2014). However, the type and concentration the organic acids influence the survival status of microorganisms (Breidt et al., 2004).

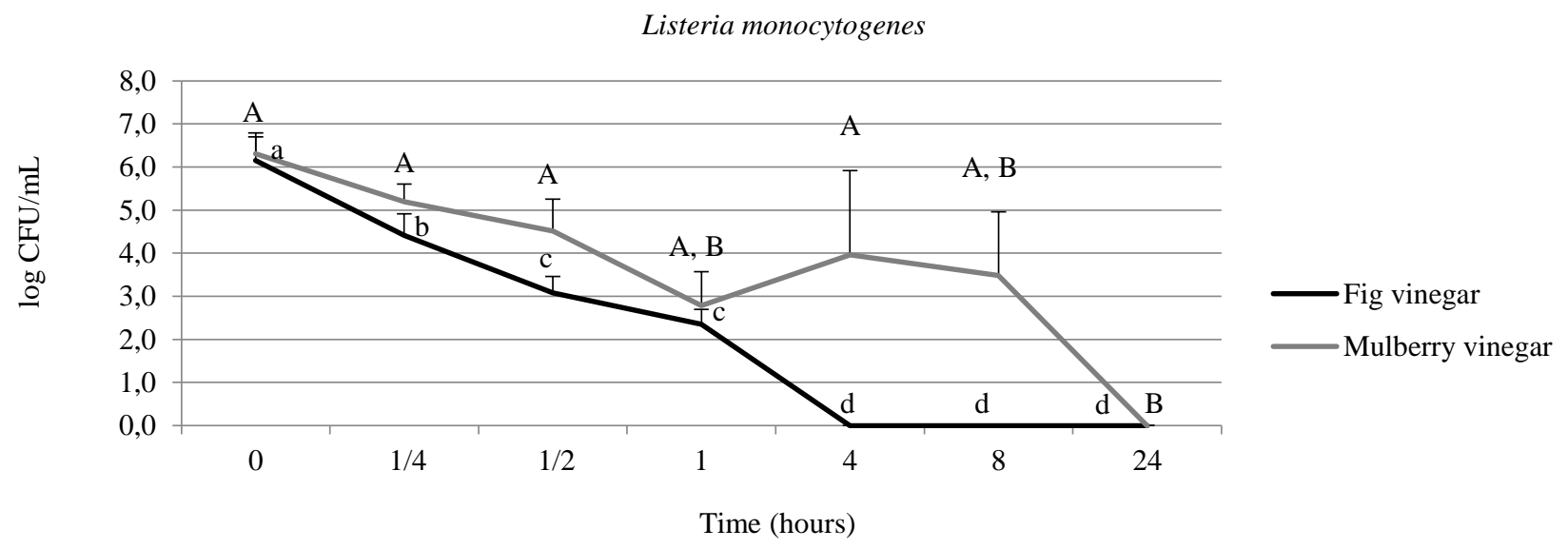

Figure 1. The survival status of Listeria monocytogenes (Log CFU/mL) in vinegar samples during 24 hours of storage at $20^{\circ} \mathrm{C}$. In the figure, means with different capital letters are significantly different for mulberry vinegar $(\mathrm{P}<0.05)$, means with different small letters are significantly different for fig vinegar $(\mathrm{P}<0.05)$.

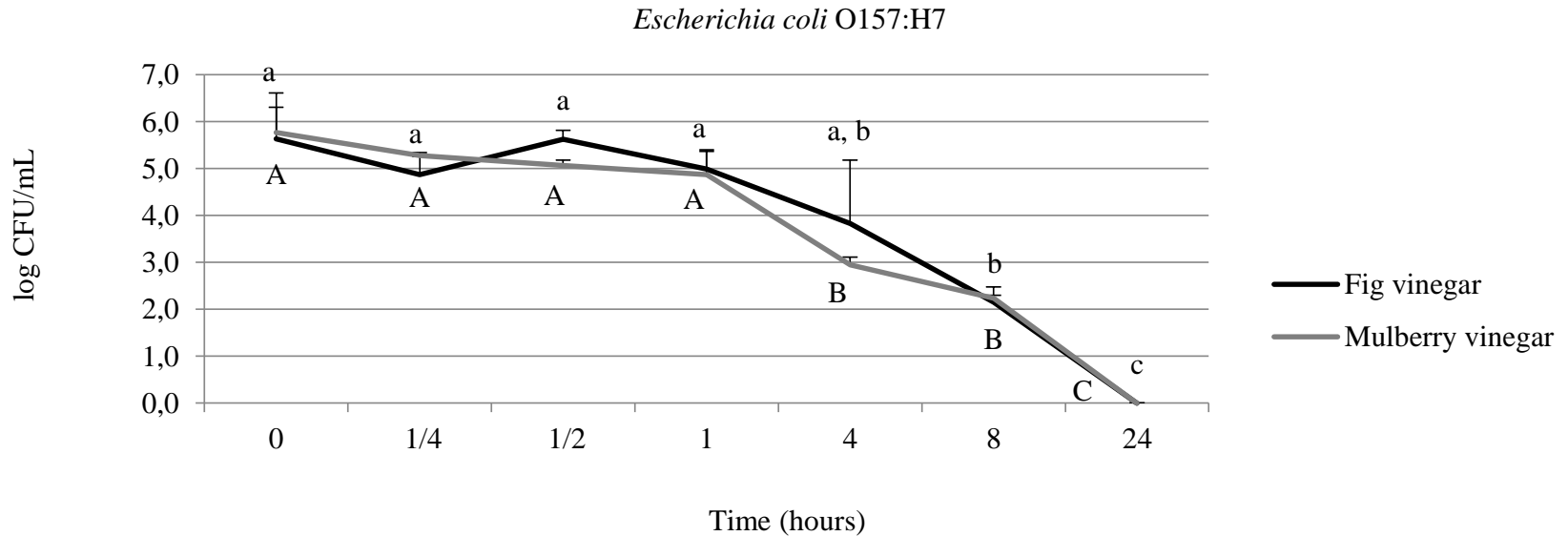

Figure 2. The survival status of Escherichia coli $\mathrm{O} 157: \mathrm{H} 7$ (Log CFU/mL) in vinegar samples during 24 hours of storage at $20^{\circ} \mathrm{C}$. In the figure, means with different capital letters are significantly different for mulberry vinegar $(\mathrm{P}<0.05)$, means with different small letters are significantly different for fig vinegar $(\mathrm{P}<0.05)$. 


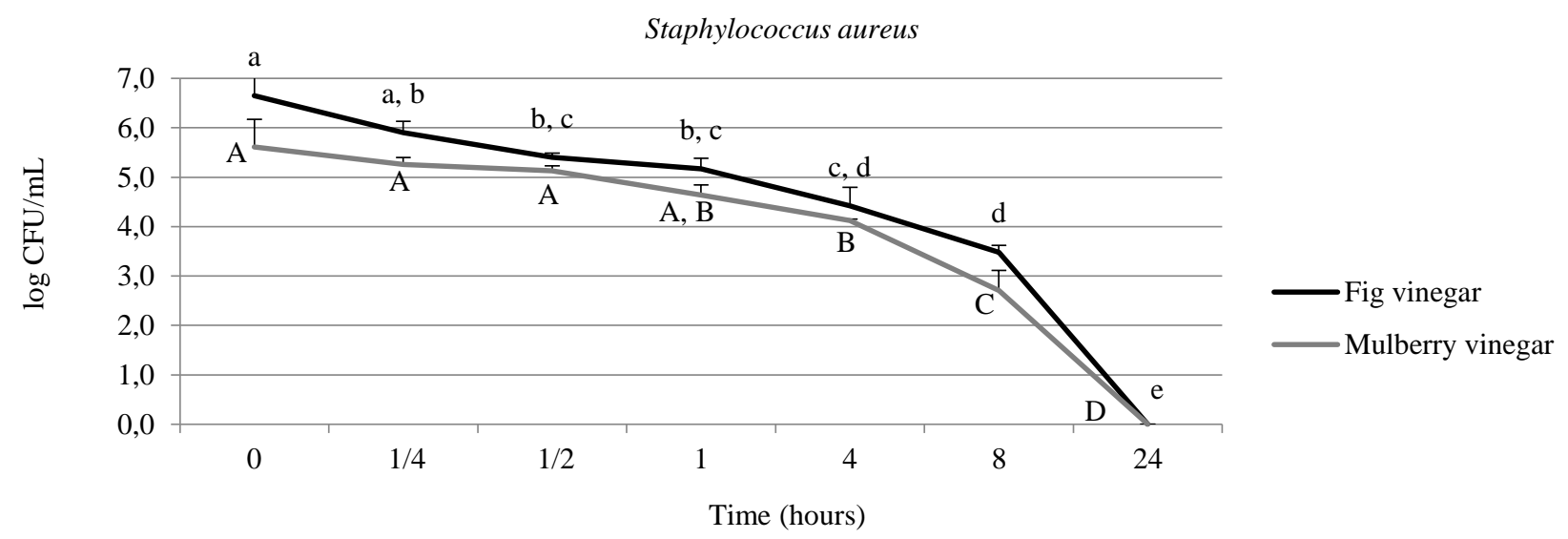

Figure 3. The survival status of Staphylococcus aureus (Log CFU/mL) in vinegar samples during 24 hours of storage at $20^{\circ} \mathrm{C}$. In the figure, means with different capital letters are significantly different for mulberry vinegar $(\mathrm{P}<0.05)$, means with different small letters are significantly different for fig vinegar $(\mathrm{P}<0.05)$.

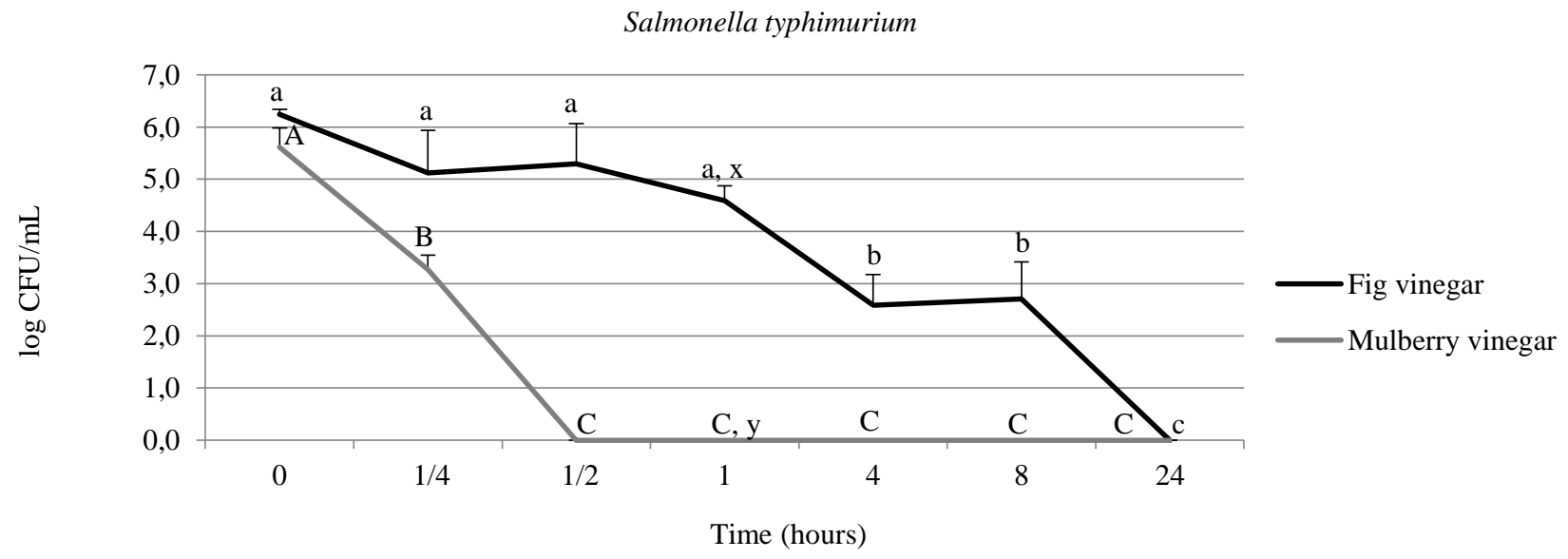

Figure 4. The survival status of Salmonella typhimurium (Log CFU/mL) in vinegar samples during 24 hours of storage at $20^{\circ} \mathrm{C}$. In the figure, means with different capital letters are significantly different for mulberry vinegar $(\mathrm{P}<0.05)$, means with different small letters are significantly different for fig vinegar $(\mathrm{P}<0.05)$, means with different letters $(x, y)$ are significantly different between vinegar samples at the same time $(\mathrm{P}<0.05)$.

After $8 \mathrm{~h}$, the numbers of $S$. aureus were $3.48 \mathrm{log}$ $\mathrm{CFU} / \mathrm{mL}$, and later it was reduced under detection limit after $24 \mathrm{~h}$ in fig vinegar. $S$. aureus was not significantly reduced in mulberry vinegar for $60 \mathrm{~min}(\mathrm{P}>0.05)$. Over 60 min exposure, the numbers of $S$. aureus were decreased to $4.12 \log \mathrm{CFU} / \mathrm{mL}, 2.71 \log \mathrm{CFU} / \mathrm{mL}$ and undetectable level for $4 \mathrm{~h}, 8 \mathrm{~h}$ and $24 \mathrm{~h}$, respectively (Figure 3 ). Hence, the antimicrobial activity of fig vinegar against $S$. aureus was similar to the results of mulberry vinegar. Acetic acid, which is known as the acid that defines the vinegar, show a good inhibitive impact against $S$. aureus in the food system or in vitro (Kim et al., 2012).

The survival status of $S$. Typhimurium in fig vinegar was not significant for the treatment times of $0,15,30$ and $60 \mathrm{~min}$ (P>0.05), as observed in E. coli O157:H7. However, $S$. Typhimurium was the most sensitive bacteria to mulberry vinegar, which was reduced to an undeterminable level within $30 \mathrm{~min}$ (Figure 4). In this study, acidity of mulberry vinegar was found higher than fig vinegar. Previous studies reported that mulberry vinegar contains higher amount of acids, mainly lactic and succinic acids, than other fruit vinegar and have potential antimicrobial and antioxidant activity (Chang et al., 2005; Karaagac et al., 2016). Hence, the highest effect of mulberry vinegar against $S$. Typhimurium could be linked with the acid sensitivity of this pathogen. The lower acid resistance of $S$. Typhimurium compared to $L$. monocytogenes and E. coli $\mathrm{O} 157: \mathrm{H} 7$ is coherent with previous studies carried on acid challenge of these microorganisms (Koutsoumanis and Sofos, 2004; Tiganitas et al., 2009).

In the literature, there is limited information on homemade vinegar and its antimicrobial properties. It was stated that homemade grape and apple vinegar showed the antimicrobial effect on E. coli $\mathrm{O} 157: \mathrm{H} 7$, L. monocytogenes, $S$. Typhimurium and $S$. aureus with inhibition zones in the range of 7.56-15.16 mm, 14.59-30.71 mm, 7.21-11.96 mm and 7.64-20.12 mm, respectively (Ozturk et al., 2015). In the 
same study, it was also detected that the antimicrobial effect of traditional homemade vinegar is lower than the industrial vinegar. In another study carried out by Bakir et al. (2017), balsamic vinegar was showed the highest antimicrobial activity against $S$. Typhimurium $(16 \mathrm{~mm})$, while the highest activity of pomegranate vinegar was observed on $S$. aureus $(13 \mathrm{~mm})$ and E. coli $(14 \mathrm{~mm})$. In another study, antimicrobial effect of mulberry vinegar was determined against variety of microorganisms including Candida albicans, Bacillus cereus, B. subtilis, Enterococcus faecalis, Erwinia carotovora, E. coli, Klebsiella oxytoca, S. aureus and Streptococcus pyogenes, by disc diffusion and microdilution assay, and the highest antimicrobial activity was observed on $S$. aureus (inhibition zone: $28 \mathrm{~mm}$ ) (Karaagac et al., 2016). All the results exhibited that the antimicrobial activity of vinegar may change depending on the test culture, the total phenolic content, and amounts of acidity of vinegar.

\section{Conclusions}

In conclusion, the survival of pathogens in homemade fig and mulberry vinegar appears not to have been studied previously. Although fig vinegar has insufficient amount of acid, it did not support the survival of pathogens longer than $24 \mathrm{~h}$ at $20^{\circ} \mathrm{C}$. The survival statuses of $L$. monocytogenes and $S$. Typhimurium in fig and mulberry vinegar were different while $E$. coli O157:H7 and $S$. aureus showed similar pattern. Mulberry vinegar was found more effective against $S$. Typhimurium than fig vinegar. The most sensitive bacteria to fig vinegar was $L$. monocytogenes, which was showed resistance to mulberry vinegar. Different behaviour of pathogens could be linked with the properties of fig and mulberry vinegar, having high amount of total phenolic content and high amount of acid content, respectively. This study showed that homemade vinegar has potential to be utilized as natural antimicrobials on food-borne pathogens and their activities change depending on acid and total phenolic contents, target microorganisms and treatment times used.

\section{References}

Anonymous. 1991. Determination of soluble solids (indirect method by refractometry). IFU-Analysis Nr. 8. International Federation of Fruit Producers. Paris.

Anonymous. 2016. Vinegar - product made from liquids of agricultural origin - definitions, requirements, marking (Vol. TS 1880 EN 13188/D1:2016). Ankara.

AOAC. 1995. Official Methods of Analysis of the Association of Official Analytical Chemistry. 16th edition. AOAC International: Washington. ISBN 0935584544.

Bachir BM, Meziant L, Benchikh Y, Louaileche H. 2014 Deployment of response surface methodology to optimize recovery of dark fresh fig (Ficus carica L., cv. Azenjar) total phenolic compounds and antioxidant activity. Food Chemistry, 162: 277-282. doi: 10.1016/j.foodchem.2014.04.054

Bakir S, Devecioglu D, Kayacan S, Toydemir G, KarbanciogluGuler F, Capanoglu E. 2017. Investigating the antioxidant and antimicrobial activities of different vinegars. European Food Research and Technology, 243(12): 2083-2094. doi: 10.1007/s00217-017-2908-0

Benjamin MM, Datta AR. 1995. Acid tolerance of enterohemorrhagic Escherichia coli. Applied and Environmental Microbiology, 61(4): 1669-1672.
Breidt JF, Hayes JS, McFeeters RF. 2004. Independent effects of acetic acid and $\mathrm{pH}$ on survival of Escherichia coli in simulated acidified pickle products. Journal of Food Protection, 67(1): 12-18. doi: 10.4315/0362-028X-67.1.12

Buchanan RL, Edelson-Mammel SG, Boyd G, Marmer BS. 2004. Influence of acidulant identity on the effects of $\mathrm{pH}$ and acid resistance on the radiation resistance of Escherichia coli O157:H7. Food Microbiology, 21(1): 51-57. doi: 10.1016/S0740-0020(03)00039-X

Budak NH. 2015. Total antioxidant activity and phenolic contents with advanced analytical techniques in the mulberry vinegar formation process. Fruit Research Institute, 2(2): 27-31.

Cemeroglu B. 2013. Food Analysis. Ankara: Food Technology Association Publications. ISBN 9786056341939.

Chang RC, Lee HC, Andi S. 2005. Investigation of the physicochemical properties of concentrated fruit vinegar. Journal of Food and Drug Analysis, 13: 348-356.

De Vero L, Gala E, Gullo M, Solieri L, Landi S, Giudici P. 2006. Application of denaturing gradient gel electrophoresis (DGGE) analysis to evaluate acetic acid bacteria in traditional balsamic vinegar. Food Microbiology 23: 809-813. doi: 10.1016/j.fm.2006.01.006

EC. 1999. Council Regulation, On the common organization of the market in wine (No 1493/1999 of 17 May 1999). Official Journal of the European Communities.

FDA. 1995. Food and Drug Administration Vinegar, definitions adulteration with vinegar eels. Available from: http://www.fda.gov/ICECI/ComplianceManuals/Compliance PolicyGuidanceManual/ucm 074471.htm/. [Accessed 01 October 2017].

FDA-BAM. 2001a. Food and Drug AdministrationBacteriological Analytical Manual, Yeasts, molds and mycotoxins. Available from: https://www.fda.gov/Food/ FoodScienceResearch/LaboratoryMethods/ucm071435.htm/. [Accessed 01 October 2017].

FDA-BAM. 2001b. Food and Drug AdministrationBacteriological Analytical Manual. Staphylococcus aureus. Available from: https://www.fda.gov/Food/FoodScienceResearch/ Laboratory Methods/ucm071429.htm/. [Accessed 01 October 2017].

FA-BAM. 2002. Food and Drug AdministrationBacteriological Analytical Manual, Enumeration of Escherichia coli and the coliform bacteria. Available from: https://www.fda.gov/Food/FoodScienceResearch /LaboratoryMethods/ucm064948.htm/. [Accessed 01 October 2017].

FDA-BAM. 2016. Food and Drug Administration-Bacteriological Analytical Manual Salmonella. Available from: https://www.fda.gov/Food/FoodScienceResearch/ Laboratory Methods/ucm070149.htm/. [Accessed 01 October 2017].

FDA-BAM. 2017. Food and Drug Administration-Bacteriological Analytical Manual Listeria monocytogenes. Available from: https://www.fda.gov/Food/FoodScienceResearch/ Laboratory Methods/ucm071400.htm/. [Accessed 01 October 2017].

Giudici P, Lemmetti F, Mazza S. 2015. Balsamic Vinegars: Tradition, Technology, Trade. In: Giudici P, Lemmetti F, Mazza S (editors). Switzerland: Springer, International Publishing. pp.: 1-167. ISBN 978-3-319-13758-2.

Giudici P, De Vero L, Gullo M. 2017. Vinegars. In: Sengun IY (editor), Acetic Acid Bacteria: Fundamentals and Food Applications. Boca Raton: CRC Press, Taylor \& Francis Group. pp.: 261-287. ISBN 9781315153490.

Gullo M, De Vero L, Giudici P. 2009. Succession of selected strains of Acetobacter pasteurianus and other acetic acid bacteria in traditional balsamic vinegar. Applied Environmental Microbiology, 75: 2585-2589. doi: 10.1128/AEM.02249-08

ISO 15214:1998. 1998. International organization for standardization, microbiology of food and animal feeding stuffsHorizontal method for the enumeration of mesophilic lactic acid bacteria-colony count technique at $30^{\circ} \mathrm{C}$. Switzerland. 
Karaagac RA, Aydogan MN, Koseoglu MS. 2016. An investigation on antimicrobial and antioxidant activities of naturally produced mulberry vinegar. Journal of Pharmaceutical Biology, 6: 34-39. doi: 10.21276/jpb

Karabiyikli S, Degirmenci H, Karapinar M. 2012. The survival of Escherichia coli O157: $\mathrm{H7}$ and Salmonella Typhimurium in black mulberry (Morus nigra) juice. African Journal of Microbiology Research, 6(48): 7464-7470. doi: 10.5897/AJMR12.1869

Karabiyikli S, Sengun IY. 2017. Beneficial Effects of Acetic Acid Bacteria and Their Food Products. In: Sengun IY (editor). Acetic Acid Bacteria: Fundamentals and Food Applications. Boca Raton: CRC Press, Taylor \& Francis Group. pp.: 321 342. ISBN 9781315153490.

Kim TJ, Silva JL, Jung YS. 2009. Antibacterial activity of fresh and processed red muscadine juice and the role of their polar compounds on Escherichia coli O157:H7. Journal of Applied Microbiology, 107: 533-539. doi: 10.1111/j.13652672.2009.04239.x

Kim BR, Yoo JH, Jung KS, Heu SG, Lee SY. 2012. Inhibitory effect of organic acids and natural occurring antimicrobials against Staphylococcus aureus isolates from various origins. Journal of Food Safety and Hygiene, 27: 449-455. doi: 10.13103/JFHS.2012.27.4.449

Koutsoumanis KP, Sofos JN. 2004. Comparative acid stress response of Listeria monocytogenes, Escherichia coli O157:H7 and Salmonella Typhimurium after habituation at different $\mathrm{pH}$ conditions. Letters in Applied Microbiology, 38: 321-326. doi: 10.1111/j.1472765X.2004.01491.x

Nastou A, Rhoades J, Smirniotis P, Makri I, Kontominas M, Likotrafiti E. 2012. Efficacy of household washing treatments for the control of Listeria monocytogenes on salad vegetables. International Journal of Food Microbiology, 159(3): 247-253. doi: 10.1016/j.ijfoodmicro.2012.09.003

Okatan V, Polat M, Askin MA. 2016. Some phyco-chemical characteristics of black mulberry (Morus nigra L.) in Bitlis. Scientific Papers-Series B, Horticulture, 60: 27-30.

Ozturk I, Calıskan O, Tornuk F, Ozcan N, Yalcin H, Baslar M, Sagdic O. 2015. Antioxidant, antimicrobial, mineral, volatile, physicochemical and microbiological characteristics of traditional homemade Turkish vinegars. LWT-Food Science and Technology, 63: 144-151. doi: 10.1016/j.lwt. 2015.03.003

Ramos B, Brandão TRS, Teixeira P, Silva CLM. 2014. Balsamic vinegar from Modena: An easy and effective approach to reduce Listeria monocytogenes from lettuce. Food Control, 42: 38-42. doi: 10.1016/j.foodcont.2014.01.029
Rosma A, Nadiah AHS, Raj A, Supwat T, Sharma S, Joshi VK. 2016. Acetic Acid Fermented Product. In: Joshi VK (editor). Indigenous Fermented Foods of South Asia. Florida: CRC Press, Taylor \& Francis Group. pp.: 598-635. ISBN 9781439887837

Sengun IY. 2013. Microbiological and chemical properties of fig vinegar produced in Turkey. African Journal of Microbiology Research, 7: 2332-2338. doi: 10.5897/AJMR12.2275

Sengun IY. 2015. Acetic Acid Bacteria in Food Fermentations. In: Montet D, Ray RC (editors). Fermented Foods: Part 1. Biochemistry and Biotechnology. Boca Raton: CRC Press, Taylor \& Francis Group. pp.: 91-111. ISBN 9780429183768. Sengun IY, Kilic G, Ozturk B. 2020. Screening physicochemical, microbiological and bioactive properties of fruit vinegars produced from various raw materials. Food Science and Biotechnology 29: 401-408. doi: 10.1007/s10068-01900678-6

Simsek M. 2010. Table fig (Ficus carica L.) selection in Mardin province of Turkey. GOÜ, Agriculture Faculty Journal, 27: 21-26.

Solieri L, Giudici P. 2009. Vinegars of World. Milan: Springer. ISBN 978-88-470-0866-3.

SPSS. 2004. Statistical package, SPSS for windows, ver. 13.0. Chicago: SPSS, Inc.

Şengün İY, Kılıç G. 2020. Total phenolic content and antibacterial activity of homemade fig and mulberry vinegar. Eskişehir Technical University Journal of Science and Technology C- Life Sciences and Biotechnology, 9(1): 89-97. doi: 10.18036/estubtdc.681028

Tiganitas A, Zeaki N, Gounadaki AS, Drosinos EH, Skandamis PN. 2009. Study of the effect of lethal and sublethal $\mathrm{pH}$ and aw stresses on the inactivation or growth of Listeria monocytogenes and Salmonella Typhimurium. International Journal of Food Microbiology, 134(1): 104-112. doi: 10.1016/j.ijfoodmicro.2009.02.016

Yang H, Hewes D, Salaheen S, Federman C, Biswas D. 2014. Effects of blackberry juice on growth inhibition of foodborne pathogens and growth promotion of Lactobacillus. Food Control, 37: 15-20. doi: 10.1016/j.foodcont.2013.08.042

Young-Soo L, Cha JD. 2010. Synergistic antibacterial activity of fig (Ficus carica) leaves extract against clinical isolates of methicillin resistant Staphylococcus aureus. Korean Journal of Microbiology and Biotechnology, 38: 405-413.

Zhao T, Doyle MP, Besser RE. 1993. Fate of enterohemorrhagic Escherichia coli $\mathrm{O} 157: \mathrm{H} 7$ in apple cider with and without preservatives. Applied and Environmental Microbiology, 59(8): 2526-2530.

Zou YX, Shen WZ, Wang SY, Liao ST, Liu F. 2015. The roles of fermentation technologies in mulberry foods processing: application and outlooks. Medicinal Chemistry, 5(4): 1-2. doi: 10.4172/2161-0444.1000e107 